\title{
Dynamics of decadal changes in the distribution of double-cropping rice cultivation in China
}

\author{
DUAN JuQi ${ }^{1,2} \&$ ZHOU GuangSheng ${ }^{1,3^{*}}$ \\ ${ }^{1}$ Chinese Academy of Meteorological Sciences, Beijing 100081, China; \\ ${ }^{2}$ School of Atmospheric Physics, Nanjing University of Information Science and Technology, Nanjing 210044, China; \\ ${ }^{3}$ State Key Laboratory of Vegetation and Environmental Change, Institute of Botany, Chinese Academy of Sciences, Beijing 100093, China
}

Received August 27, 2012; accepted October 30, 2012; published online January 10, 2013

\begin{abstract}
Quantitative description of changes in the distribution of paddy rice cultivation in response to recent climate change provides a reference for rice cultivation patterns and formulation of countermeasures to cope with future climate change in China. This study analyzes the dynamics of decadal changes in distribution of double-cropping rice in China during 1961-2010 in relation to climate change based on the maximum entropy method. Decadal changes in the double-cropping rice cultivation area and climatic suitability in China were apparent. The total area of climatically suitable regions was highest in the 1960s, and subsequently showed an increasing trend at first and then a decreasing trend from the 1970s to 2000s. However, the low climatic suitability area decreased, which implied that the moderate and high climatic suitability areas increased. Among the latter, the high climatic suitability area showed the highest increase in extent to 4.4 times that of the 1990s and four times that of the 1960s. The areas of double-cropping rice cultivation most sensitive to climate change are mainly located in central Jiangsu, central Anhui, the eastern Sichuan Basin, southern Henan and central Guizhou. Transformation of areas between low and moderate climatic suitability was observed in northern Zhejiang, southern Anhui and Hubei, and northern Guangxi. Transformation of areas between moderate and high climatic suitability was observed in central Jiangxi and Leizhou Peninsula. The northern boundary of double-cropping rice cultivation in China shifted southwards and contracted eastwards in the 1970s, and extended northwards in the 1980s. However, the northern boundary did not shift northwards in response to climate warming in the 2000s.
\end{abstract}

double-cropping rice, cultivation distribution, decadal, dynamics

Citation: Duan J Q, Zhou G S. Dynamics of decadal changes in the distribution of double-cropping rice cultivation in China. Chin Sci Bull, 2013, 58: 1955-1963, doi: 10.1007/s11434-012-5608-y

Global climate change has resulted in a clear trend for increase and decadal variation in air temperature in China, especially since the 1980s [1,2], and a change in precipitation patterns [3]. Decadal climate anomalies affect the planting patterns of agricultural crops and people's lives directly, and result in the degradation of natural ecosystems in some regions [4,5] and even social stability [6]. Thus, decadal climate variability and its impact has become an important focus of climate research [7-9].

The cropping system used in an area depends on the interaction between crop climatic adaptability and human activities. The climatic adaptability of crops is the basis for

*Corresponding author (email: gszhou@cams.cma.gov.cn) crop planting patterns. The regionalization of climatic suitability and climatic ecology have been important issues in agricultural climate research [10-12]. Rice is among the most important food crops worldwide, especially in China, and is the staple of more than half of the world's population and more than $65 \%$ of the population in China. At the national level, the regionalization of paddy rice cultivation and its climatic requirements was presented by Ding [13] in the 1950s and the Group of Chinese Agriculture Climate Division [10] in the 1980s, respectively, and plays an important role in guiding rice production in China. Recently, a climate suitability regionalization of double-cropping rice at the national level was presented by Duan and Zhou [14] on the basis of a comprehensive index of rice appearance frequen- 
cy. This regionalization presents the potential distribution of rice cultivation under average climatic conditions, and provides the basis for scientific direction of rice production.

Present-day climatic warming is obvious in China. As a result, the area of rice cultivation is decreasing in southern China and increasing in northern China, and the boundary of rice cultivation is shifting northwards $[15,16]$. In general, climate change results in the movement of plant species distribution towards the poles and higher altitude regions $[17,18]$ and changes in vegetation types [17]. The geographical distribution of plant species and plant functional types will change under future climate change scenarios [19-21]. The boundaries of double-crop rice cultivation in China have moved northwards because of the rising temperature since the 1980s [22]. However, some studies suggest that a change in water balance is an important factor that affects the distribution of plant species and may have the opposite effect as rising temperature [23]. Interannual climate variability is an important factor that affects the geographical distribution of vegetation, especially annual herbs [24]. Therefore, clarification of the relationship between climate change and the distribution of rice cultivation is required urgently to provide a reference for rice cultivation patterns and to aid development of strategies to cope with climate change in China.

Duan and Zhou [14] revealed the dominant climatic factors that affect the distribution of double-cropping rice cultivation and developed a method for classification of double-cropping rice climatic suitability in terms of the maximum entropy method. However, the responses in the climatic suitability of double-cropping rice cultivation distribution in China to climate change have not been analyzed previously. In the present study, based on the correspondence of double-cropping rice cultivation with agrometeoro- logical observations during 1999-2010 and climate data for the period 1961-2010, together with the method of doublecropping rice climatic suitability classification, the dynamics of decadal changes in the distribution of double-cropping rice cultivation in China during the period 1961-2010 was analyzed. The results reveal responses in the distribution of double-cropping rice cultivation to decadal climate change, and provide a reference for rice cultivation patterns and formulation of countermeasures to climate change in China.

\section{Data and methods}

\subsection{Data collection and processing}

Data for double-cropping rice geographical distribution and climate in China were obtained from the National Meteorological Information Center, China Meteorological Administration (CMA). The data were recorded at 46 doublecropping rice agrometeorological observation stations from 1999 to 2010 and 741 meteorological observation stations from 1961 to 2010. Average daily temperature and daily precipitation were interpolated into $10 \mathrm{~km} \times 10 \mathrm{~km}$ grids, in terms of the truncated Gaussian filter operator space convolution algorithm [25] and a decreasing air temperature vertical gradient of $-0.006^{\circ} \mathrm{C} / \mathrm{m}$. The location of the weather stations, double-cropping rice stations, and terrain in China are shown in Figure 1. Data processing was performed with ArcGIS 9.3 software.

\subsection{Methods}

The maximum entropy model (as implemented in the MaxEnt version 3.3.3a software; (http://www.cs.princeton.
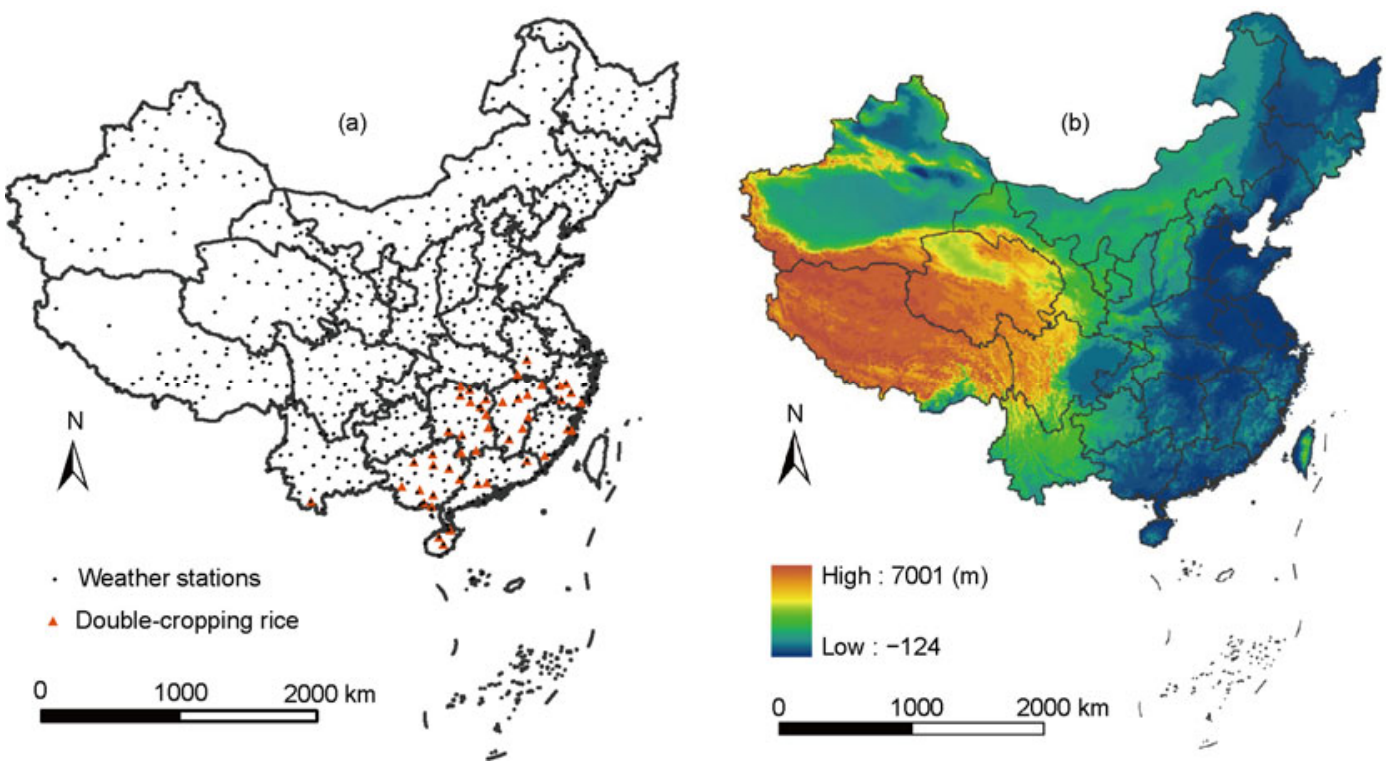

Figure 1 Location of climate and double-cropping rice observation stations (a) and the terrain in China (b). 
edu/ schapire/maxent/) was used, which was developed by Phillips and Dudik [26] for simulation of the distribution of plant species. The software uses the maximum entropy approach to infer, without bias, plant species distribution based on limited information on the distribution of unknown plant species. The model considers that in the absence of external forces, an entity always tends to a maximum within applied constraints. Under known conditions, the entities with maximum entropy are close to the real state [27]. Maximum entropy statistical modeling seeks to select the maximum entropy distribution as the optimal distribution from a qualified distribution. Details of the method are described in $[14,26]$.

The present study indicated that the dominant climatic factors that affect double-cropping rice distribution in China are annual precipitation, mean temperature of the warmest month, and days with stable temperature not less than $18^{\circ} \mathrm{C}$, and that these variables could be used as environment inputs in the MaxEnt model [14]. The MaxEnt method calculates the crop appearance frequency $(P)$ in an area within the range of 0 to 1 , which is the reference from the possibility of assessment division reported by the Intergovernmental Panel on Climate Change (IPCC). The climatic suitability classes for double-cropping rice cultivation and their respective appearance frequencies were defined as follows: climatically unsuitable $(P<0.05)$, low climatic suitability $(0.05 \leqslant P<0.33)$, moderate climatic suitability $(0.33 \leqslant P<0.66)$, and high climatic suitability $(P \geqslant 0.66)$. An appearance frequency of $P \geqslant 0.05$ was considered to be the total climatically suitable class for double-cropping rice cultivation. The northern boundary of double-cropping rice cultivation was
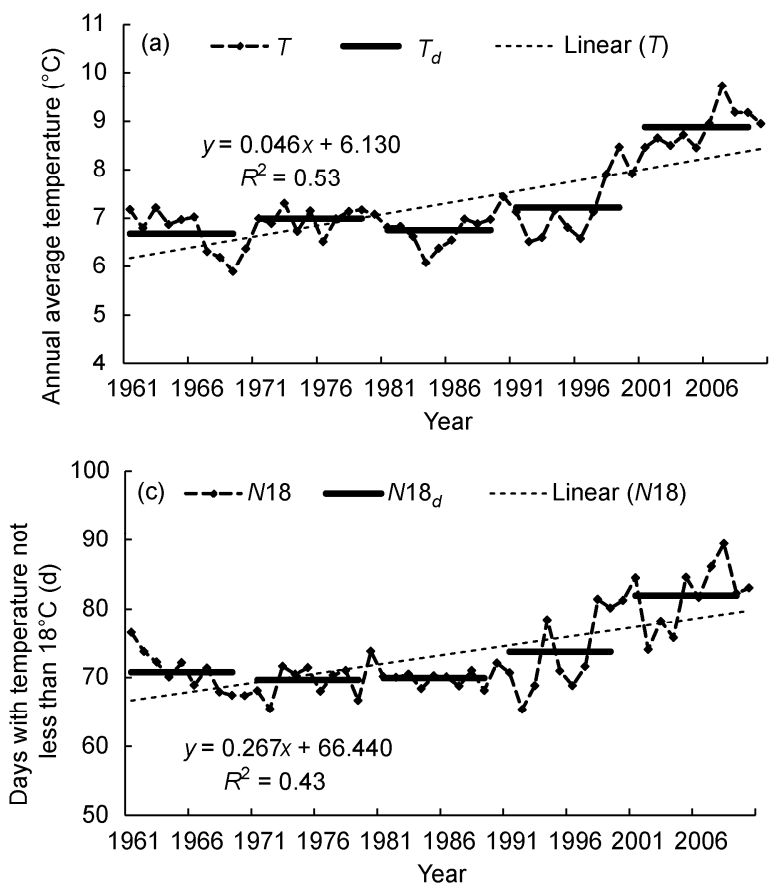

given by $P=0.05[14,28]$. The period $1961-1970$ was divided into five decades, namely the 1960s, 1970s, 1980s, 1990 s, and 2000s. Decadal changes in the distribution of double-cropping rice cultivation during 1961-2010 were obtained based on the average of ten random sampling simulations of the maximum entropy model, in terms of data for a standard annual climate comprising annual precipitation, mean temperature of the warmest month, and days with a stable temperature not less than $18^{\circ} \mathrm{C}$ during the period 1971-2000. Eighty percent of the 46 double-cropping rice agrometeorological observation stations were used as training data for the simulation, and the remaining $20 \%$ were used as validation data for the simulation model. The changes in each climatic suitability class and the northern boundary of double-cropping rice cultivation in China were mapped with ArcGIS 9.3 software.

\section{Results}

\subsection{Regional climate change in China}

The annual average temperature showed a rising trend in China during 1961-2010 with an average rate of increase of $0.046^{\circ} \mathrm{C} / \mathrm{a}$ (Figure 2(a)). Decadal change in temperature showed an increasing trend in the 1970s, a declining trend in the 1980s, and continuous increasing trend during the 1990 s and 2000s. Changes in days with a stable temperature not less than $18^{\circ} \mathrm{C}$ and mean temperature of the warmest month showed the same trend as the annual average temperature, with rates of increase of $0.267 \mathrm{~d} / \mathrm{a}$ and $0.036^{\circ} \mathrm{C} / \mathrm{a}$, respectively (Figure 2(c),(d)). The regional annual precipitation
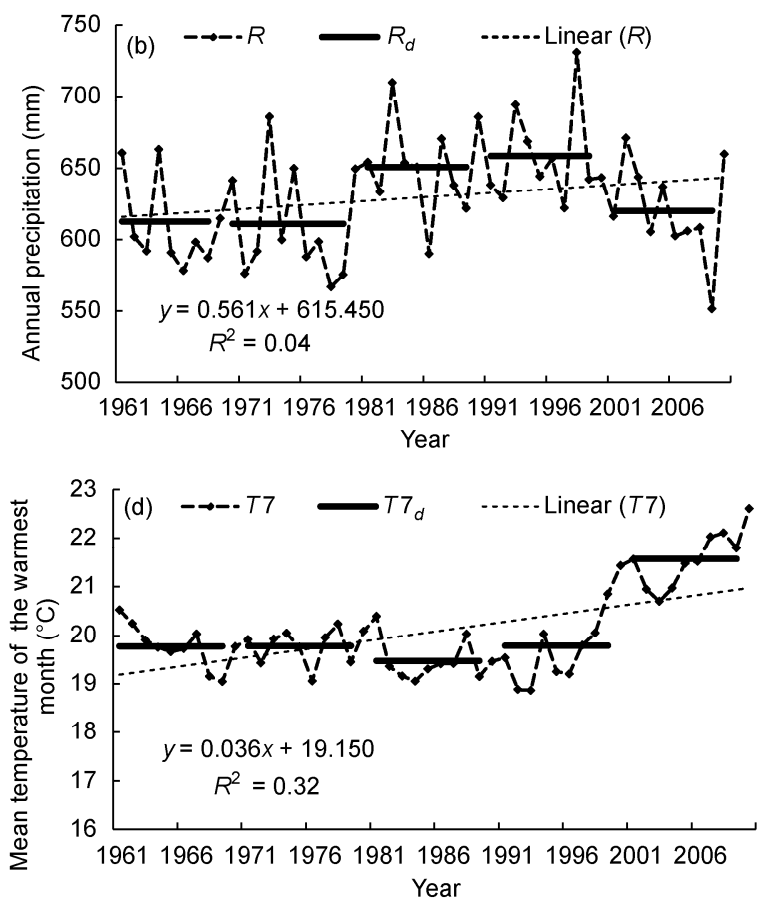

Figure 2 Annual and decadal climate change in China. (a) Annual average temperature; (b) annual precipitation; (c) days with temperature not less than $18^{\circ} \mathrm{C}$; (d) mean temperature of the warmest month. 
increased slightly with an average rate of increase of 0.56 mm/a during 1961-2010 (Figure 2(b)). Decadal precipitation showed no obvious change during the 1960s and 1970s, then increased in the 1980s and 1990s, but declined in the 2000s. Similar changes in annual average temperature and precipitation have been reported previously $[2,29]$.

\subsection{Decadal changes in distribution of double-cropping rice cultivation}

The inter-decadal changes in climatic suitability areas for double-cropping rice in China were identified under different decadal climatic conditions (Figure 3). With regard to comparison of the 1960s and 1970s, the low climatic suitability area migrated southwards in Jiangsu, Anhui, Henan and Hubei, and migrated eastwards in Guizhou and Sichuan. In Hunan, the low climatic suitability area expanded eastwards and the moderate climatic suitability area decreased. The climatic suitability of Leizhou Peninsula for double-cropping rice decreased from high to moderate. From the 1970 s to the 1980 s, the low climatic suitability area migrated southwards to the same position of the 1960s in Jiangsu, Anhui, Henan and Hubei; the climatically unsuitable area expanded eastwards into the originally low climatic suitability area in Guizhou; the moderate climatic suitability area shifted northwards into the originally low climatic suitability area in Zhejiang; and the climatic suitability of Leizhou Peninsula increased from moderate to high. Between the 1980s and 1990s, the northern boundary of the low climatic suitability area showed no obvious change in Jiangsu, Anhui, Henan and Hubei, but shifted westwards in
Guizhou; the high climatic suitability area in Guangxi decreased to moderate climatic suitability, and part of the high climatic suitability area in Jiangxi decreased to moderate climatic suitability. The overall area of high climatic suitability increased because of the change from moderate to high climatic suitability in some areas in the 2000s.

\subsection{Changes in distribution of climatic suitability classes for double-cropping rice cultivation}

Changes in the distribution of climatic suitability classes for double-cropping rice cultivation inevitably led to changes in the area of each class. From the 1960s to 2000s, the climatically unsuitable area was lowest in the 1960s, increased in the 1970s, then decreased, and subsequently increased again in the 2000s (Table 1). The change in the total climatically suitable area showed the opposite trend to that of the climatically unsuitable area. The total area climatically suitable for double-cropping rice cultivation was highest in the 1960 s with an area of $1953.0 \times 10^{3} \mathrm{~km}^{2}$ and thereafter decreased. The area of low climatic suitability showed a declining trend, from $1067.7 \times 10^{3} \mathrm{~km}^{2}$ in the 1960 s to $738.3 \times$ $10^{3} \mathrm{~km}^{2}$ in the $1970 \mathrm{~s}$. The regions with moderate and high climatic suitability are the main areas of double-cropping rice production in China; the total area of these two climatic suitability classes showed an increasing trend from 885.3 $\times 10^{3} \mathrm{~km}^{2}$ in the 1960 s to $1067.4 \times 10^{3} \mathrm{~km}^{2}$ in the 2000s. The high climatic suitability class showed inter-decadal fluctuations in area and increased most greatly in the 2000s, when the area was about 4.4 times that of the 1990s and about four times that of the 1960s.
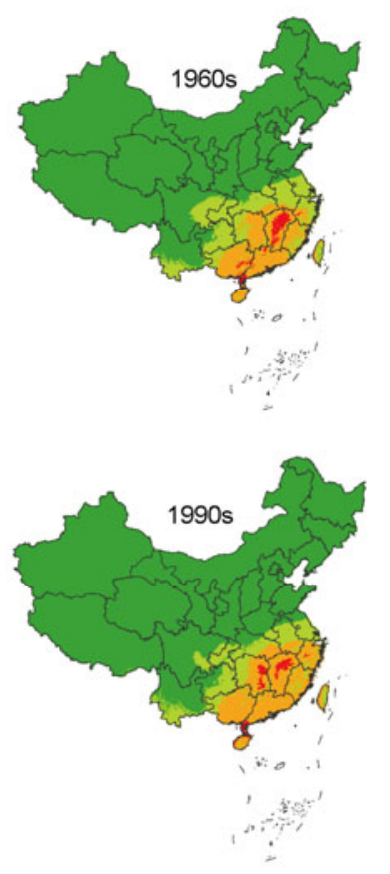
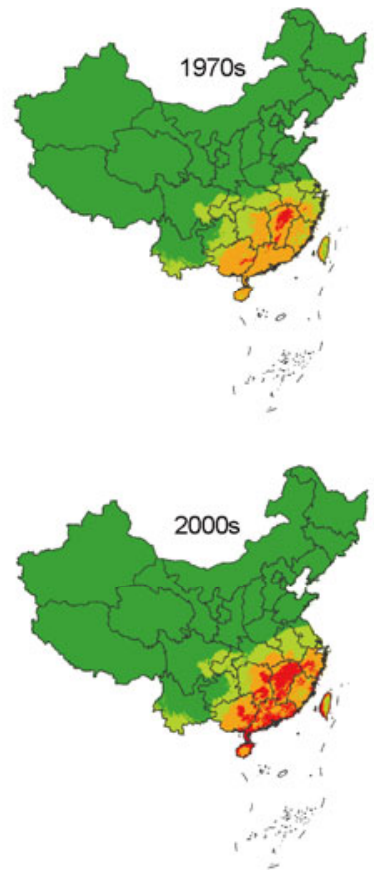
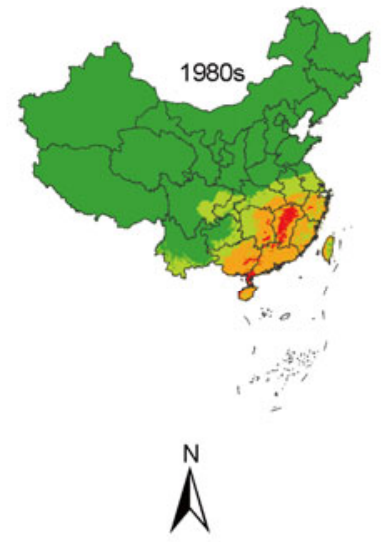

Climatic unsuitability

Low climatic suitability

Moderate climatic suitability

High climatic suitability

0

2300

$4600 \mathrm{~km}$

Figure 3 Decadal distribution of different climatic suitability classes for double-cropping rice cultivation in China during the period 1961-2010. 
Table 1 Area of each climatic suitability class for double-cropping rice cultivation in China in each decade from 1961 to 2010 (unit: $\times 10^{3} \mathrm{~km}{ }^{2}$ )

\begin{tabular}{cccccc}
\hline Class of climatic suitability & $1960 \mathrm{~s}$ & $1970 \mathrm{~s}$ & $1980 \mathrm{~s}$ & $1990 \mathrm{~s}$ & 7862.0 \\
\hline Unsuitable & 7764.7 & 7932.6 & 7886.7 & 874.1 & 833.8 \\
Low & 1067.7 & 895.3 & 839.3 & 738.3 & 738.6 \\
Moderate & 795.2 & 835.9 & 117.6 & 83.3 \\
High & 90.1 & 53.9 & 366.4 & 83.0 \\
\hline
\end{tabular}

Both the climatically unsuitable and moderate climatic suitability classes increased in area in the 1970 s, which corresponded to a decrease in the areas of the low and high climatic suitability classes. Both the climatically unsuitable and low climatic suitability classes declined in the 1980s, which corresponded to an increase in the area of the high climatic suitability class from $53.9 \times 10^{3} \mathrm{~km}^{2}$ to $117.6 \times 10^{3}$ $\mathrm{km}^{2}$. The moderate climatic suitability class did not change obviously in area in the 1980s. The climatically unsuitable class continued to decrease in area in the 1990s, which corresponded with an increase in the moderate climatic suitability area. Simultaneously, the low and high climatic suitability classes also decreased in area in the 1990s. The climatically unsuitable and high climatic suitability classes increased in area in the 2000s; in particular, the high climatic suitability area was about 3.4 times higher than that in the 1990s. Simultaneously, the moderate and low climatic suitability classes decreased in area.

The dynamics of decadal changes in each climatic suitability area are summarized in Table 2 . The first column of the left side is the climatic suitability for double-cropping rice in the previous decade; the first row of the table is the climatic suitability for double-cropping rice in the next decade. The value of $y_{i j}$, where $i$ and $j$ are the row and column, respectively, indicates the area occupied by the $i$ climatic suitability class in the previous decade, represented by the area occupied by $j$ climatic suitability class in the next decade. The area unit is $10^{3} \mathrm{~km}^{2}$. The sum of the values in each row indicates the area of $i$ climatic suitability class in the previous decade; the sum of the values in each col- umn indicates the area of $j$ climatic suitability class in the next decade.

The conversions between climatic suitability classes resulted in changes in the area of the different climatic suitability classes (Table 2). With regard to comparison of the 1960s and 1970s, the areas of unchanged climatic suitability were $7763.8 \times 10^{3} \mathrm{~km}^{2}, 850.2 \times 10^{3} \mathrm{~km}^{2}, 750.1 \times 10^{3} \mathrm{~km}^{2}$, and $53.0 \times 10^{3} \mathrm{~km}^{2}$ for the climatically unsuitable to the high suitability classes, respectively. From the 1960s to the 1970 s, the climatically unsuitable class increased in area from $7764.7 \times 10^{3} \mathrm{~km}^{2}$ to $7932.6 \times 10^{3} \mathrm{~km}^{2}$, an increase of $167.9 \times 10^{3} \mathrm{~km}^{2}$ (Table 1), which reflected decline from low climatic suitability $\left(168.8 \times 10^{3} \mathrm{~km}^{2}\right)$ and upgrade to low suitability $\left(0.9 \times 10^{3} \mathrm{~km}^{2}\right)$ from the previous decade (Table 2 ). The low climatic suitability class (the sum of the second column) decreased in area, which reflected upgrade from climatically unsuitable $\left(0.9 \times 10^{3} \mathrm{~km}^{2}\right)$, decline from moderate climatic suitability $\left(44.2 \times 10^{3} \mathrm{~km}^{2}\right)$, degradation to climatically unsuitable $\left(168.8 \times 10^{3} \mathrm{~km}^{2}\right)$, and upgrade to moderate climatic suitability $\left(48.7 \times 10^{3} \mathrm{~km}^{2}\right)$. The moderate climatic suitability area increased slightly, which comprised upgrade of $48.7 \times 10^{3} \mathrm{~km}^{2}$ from low climatic suitability, degradation of $37.1 \times 10^{3} \mathrm{~km}^{2}$ from high climatic suitability, degradation of $44.2 \times 10^{3} \mathrm{~km}^{2}$ to low climatic suitability, and upgrade of $0.9 \times 10^{3} \mathrm{~km}^{2}$ to high climatic suitability. The area of high climatic suitability was reduced by about $50 \%$, consisting of degradation of $37.1 \times 10^{3} \mathrm{~km}^{2}$ to moderate climatic suitability, and upgrade of only $0.9 \times 10^{3} \mathrm{~km}^{2}$ to high climatic suitability from the other classes.

From the 1970 s to 1980 s, the area of unchanged climatic

Table 2 Decadal conversions between the different climatic suitability classes for double-cropping rice cultivation in China from 1961 to 2010 (Unit: $\times 10^{3}$ $\mathrm{km}^{2}$ )

\begin{tabular}{|c|c|c|c|c|c|c|c|c|}
\hline & \multicolumn{4}{|c|}{$1960 \mathrm{~s}-1970 \mathrm{~s}$} & \multicolumn{4}{|c|}{ 1970s-1980s } \\
\hline & Not & Low & Middle & High & Not & Low & Middle & High \\
\hline Not & 7763.8 & 0.9 & 0 & 0 & 7843.2 & 89.4 & 0 & 0 \\
\hline Low & 168.8 & 850.2 & 48.7 & 0 & 43.5 & 752.9 & 98.9 & 0 \\
\hline Middle & 0 & 44.2 & 750.1 & 0.9 & 0 & 31.8 & 740.3 & 63.8 \\
\hline \multirow[t]{3}{*}{ High } & 0 & 0 & 37.1 & 53.0 & 0 & 0 & 0.1 & 53.8 \\
\hline & \multicolumn{4}{|c|}{$1980 \mathrm{~s}-1990 \mathrm{~s}$} & \multicolumn{4}{|c|}{$1990 \mathrm{~s}-2000 \mathrm{~s}$} \\
\hline & Not & Low & Middle & High & Not & Low & Middle & High \\
\hline Not & 7810.6 & 76.1 & 0 & 0 & 7827.2 & 34.8 & 0 & 0 \\
\hline Low & 51.4 & 756.1 & 66.6 & 0 & 84.8 & 662.1 & 86.9 & 0 \\
\hline Middle & 0 & 1.6 & 815.8 & 21.9 & 0 & 41.4 & 609.3 & 287.9 \\
\hline High & 0 & 0 & 56.2 & 61.4 & 0 & 0 & 48 & 78.5 \\
\hline
\end{tabular}


suitability was $7843.2 \times 10^{3} \mathrm{~km}^{2}, 752.9 \times 10^{3} \mathrm{~km}^{2}, 740.3 \times 10^{3}$ $\mathrm{km}^{2}$ and $53.8 \times 10^{3} \mathrm{~km}^{2}$ for the climatically unsuitable to high climatic suitability classes, respectively. The highest increase in area occurred in the high climatic suitability class, which increased from $53.9 \times 10^{3} \mathrm{~km}^{2}$ to $117.6 \times 10^{3}$ $\mathrm{km}^{2}$. This increase was mainly due to change from moderate climatic suitability. The climatically unsuitable area decreased by $45.9 \times 10^{3} \mathrm{~km}^{2}$ mainly owing to upgrade to low climatic suitability. The low climatic suitability area decreased slightly, mainly due to upgrade to moderate climatic suitability. The moderate climatic suitability area did not change markedly.

From the 1980s to 1990 s, the area of unchanged climatic suitability was $7810.6 \times 10^{3} \mathrm{~km}^{2}, 756.1 \times 10^{3} \mathrm{~km}^{2}, 815.8 \times 10^{3}$ $\mathrm{km}^{2}$ and $61.4 \times 10^{3} \mathrm{~km}^{2}$ for the climatically unsuitable to high climatic suitability classes, respectively, which accounted for about $97.2 \%$ of the total land area in China. The low climatic suitability area decreased as a result of degradation to low climatic suitability $\left(51.4 \times 10^{3} \mathrm{~km}^{2}\right)$ and upgrade to moderate climatic suitability $\left(66.6 \times 10^{3} \mathrm{~km}^{2}\right)$, and upgrade of $77.7 \times 10^{3} \mathrm{~km}^{2}$ from climatic unsuitability to low climatic suitability. The moderate climatic suitability area increased, which comprised upgrade of $66.6 \times 10^{3} \mathrm{~km}^{2}$ from low climatic suitability, degradation of $56.2 \times 10^{3} \mathrm{~km}^{2}$ from high climatic suitability, and conversion of $1.6 \times 10^{3} \mathrm{~km}^{2}$ and $21.9 \times 10^{3} \mathrm{~km}^{2}$ from moderate to low and high climatic suitability, respectively. The high climatic suitability area was reduced by one-third because of conversion to moderate climatic suitability.

From the 1990s to the 2000s, the area of unchanged climatic suitability was $7827.2 \times 10^{3} \mathrm{~km}^{2}, 662.1 \times 10^{3} \mathrm{~km}^{2}$, $609.3 \times 10^{3} \mathrm{~km}^{2}$, and $78.5 \times 10^{3} \mathrm{~km}^{2}$ for the climatically unsuitable to high climatic suitability classes, respectively, which accounted for $94.4 \%$ of the total land area in China. The climatically unsuitable area increased, which comprised degradation of $84.8 \times 10^{3} \mathrm{~km}^{2}$ from low climatic suitability and upgrade of $34.8 \times 10^{3} \mathrm{~km}^{2}$ to low climatic suitability. The high climatic suitability class showed the highest increase in area, to about 4.4 times that of the 1990s, which comprised upgrade of $287.9 \times 10^{3} \mathrm{~km}^{2}$ from moderate climatic suitability and degradation of $48.0 \times 10^{3} \mathrm{~km}^{2}$ from high climatic suitability.

\subsection{Dynamics of changes in sensitivity to climate change and the northern boundary of double-cropping rice cultivation}

Decadal sensitivity of areas of double-cropping rice cultivation to climate change was apparent (Figures 3 and 4). The change in the area of the different climatic suitability classes comprised about $2.8 \%-5.6 \%$ of the total land area. The greatest change in area $(5.6 \%)$ occurred during the 2000s. The areas of double-cropping rice cultivation that were most sensitive to climatic change were mainly located in central Jiangsu, central Anhui, the eastern Sichuan Basin, southern
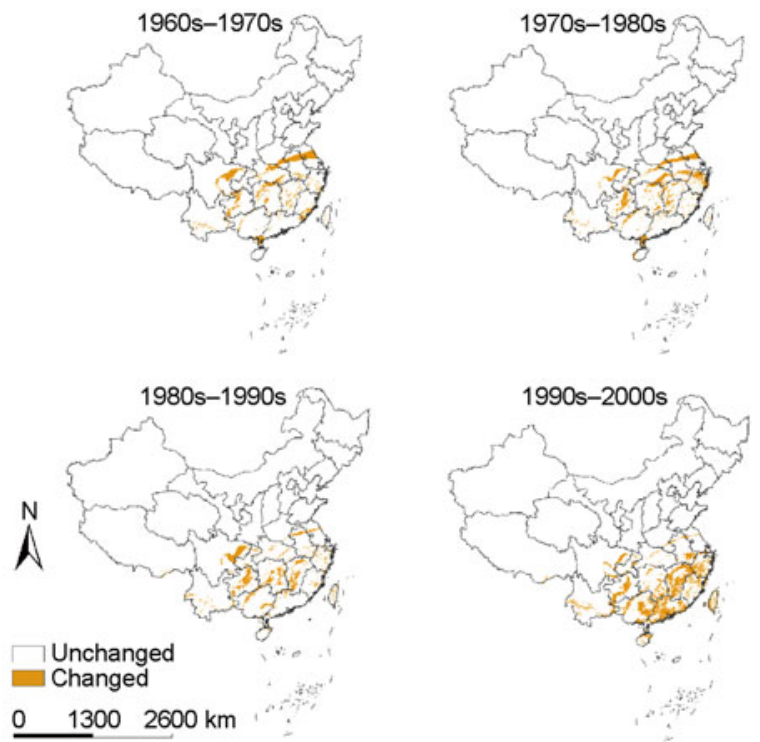

Figure 4 Decadal sensitivity of double-cropping rice to climate change.

Henan, and central Guizhou. Simultaneously, transformation of areas between low and moderate climatic suitability occurred in northern Zhejiang, southern Anhui and Hubei, and northern Guangxi. Transformation of areas between moderate and high climatic suitability occurred in central Jiangxi and Leizhou Peninsula.

The northern boundary of rice cultivation directly affects the production pattern, and its adjustment is important for guide rice production patterns. Our results showed that $P=0.05$, based on the maximum entropy method, effectively represents the northern boundary of double-cropping rice cultivation [13]. Thus, the northern boundary lay in the line connecting Jiangsu-Anhui-Henan-Hubei-Sichuan-Guizhou-Yunnan and fluctuated under different decadal climatic conditions (Figure 5). From the 1960s to 1970s, the northern boundary shifted southwards by about $0.5^{\circ}-1.5^{\circ}$ latitude in Jiangsu, Anhui, and southern Henan, and by

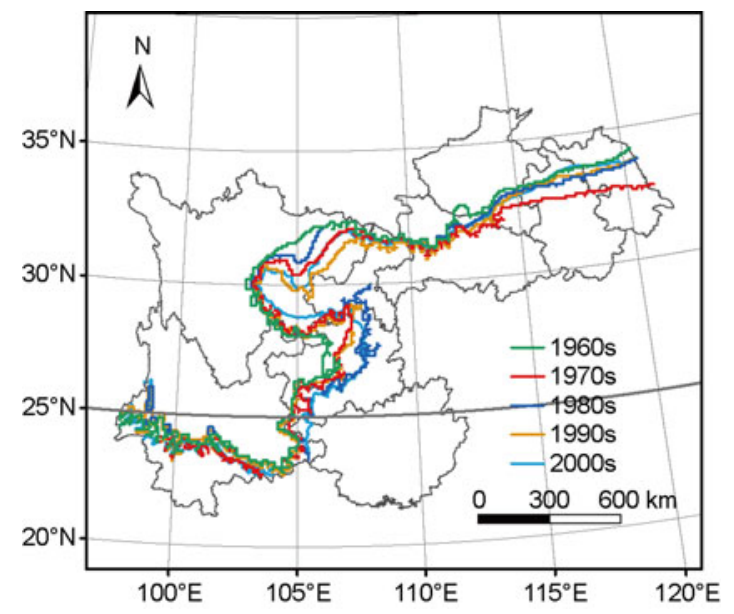

Figure 5 Decadal changes in the northern boundary of double-cropping rice cultivation. 
about $0.5^{\circ}$ latitude in the eastern Sichuan Basin, and contracted eastwards by about $0.5^{\circ}-1^{\circ}$ longitude in Guizhou. In the 1980s the northern boundary returned to that of the $1960 \mathrm{~s}$, but contracted eastwards by about $1^{\circ}$ longitude in Guizhou. The northern boundary in the 1990s was similar to that of the $1980 \mathrm{~s}$, but it shifted southwards by about $1^{\circ}$ latitude in eastern Sichuan and westwards by about $0.5^{\circ}$ longitude in Guizhou. In the 2000s, the northern boundary shifted slightly northwards in eastern Sichuan and contracted slightly eastwards in Guizhou. The boundary was similar to, or had moved slightly southwards, compared to that of the 1960s.

\subsection{Relationship between decadal changes in area of double-cropping rice cultivation and climate}

Plant distribution greatly reflects climate, especially temperature and moisture conditions at the regional scale. The relationship between the decadal changes in area of doublecropping rice cultivation and climate were analyzed in terms of the number of days with a stable temperature not less than $18^{\circ} \mathrm{C}$ and annual precipitation. The correlation coefficient values and signs between each climatic suitability class and both climatic variables were inconsistent, which indicated that interaction between temperature and moisture affects the distribution of double-cropping rice cultivation, and the effects of the two climatic variables may be opposite (Table 3 ). In particular, the high climatic suitability class showed a significantly positive correlation with temperature, and a negative correlation with moisture, which indicated that increased temperature significantly promotes expansion of the high climatic suitability area for doublecropping rice cultivation in China, but this response is constrained by precipitation.

\section{Discussion}

Decadal intervals and changes in the area of climatic suitability for double-cropping rice cultivation in relation to climatic suitability classes were incorporated in a maximum entropy model in the present study. The total area climatically suitable for double-cropping rice cultivation was highest in the 1960s, and subsequently the area showed an increasing trend at first and then a decreasing trend from the 1970 s to 2000s. However, the low climatic suitability area decreased, which implied that the moderate and high climatic suitability areas increased in extent. Among the latter, the increase in area was greatest for the high climatic suitability class, which was about 4.4 times the area of the $1990 \mathrm{~s}$ and four times that of the 1960s.

Agroecosystems are constrained by climatic conditions. Climate warming, drying or wetting will result in changes to agricultural patterns. Climate changes in recent decades are apparent in China under the background of global warming, and show a warming trend overall and decadal variability (Figure 2) [2,30]. The present study demonstrated that the areas of double-cropping rice cultivation seriously affected by climatic changes in recent decades are mainly located in Jiangsu, central Anhui, the eastern Sichuan Basin, southern Henan, Guizhou, and southern Yunnan. Considering the effects of humidity and temperature changes [31], the cultivation area of subtropical crops might be expected to shift northwards as a result of global warming, but water is a major limiting factor in the northern part of the subtropical crop cultivation area. Paddy rice cultivated in the southcentral plateau region in Yunnan is located in a subtropical drought-prone area and would be limited because of water shortage resulting from global warming [31]. The present results indicated that transformation between areas of low and moderate climatic suitability for double-cropping rice cultivation was observed in northern Zhejiang, southern Anhui and Hubei, and northern Guangxi. Transformation between areas of moderate and high climatic suitability was observed in central Jiangxi and Leizhou Peninsula. Temporal and spatial differences in rice production in response to recent climatic change in China are reported [32]. The middle and lower reaches of the Yangtze River is an efficient agroecological system vulnerable to damage under climate warming and increased precipitation [31]. Rice yields are predicted to be reduced in the Huaihe River valley, the middle and lower reaches of the Yangtze River, and its southern area as a result of climatic change [33]. The rice production area in Jiangxi exhibits low or moderate sensitivity to climatic change [34]. The present results show that the climatic suitability for double-cropping rice has increased with rising temperature and decreasing precipitation in most areas south of the Yangtze River in the 2000s [2].

Table 3 Correlation between decadal changes in area of double-cropping rice cultivation and two climatic variables

\begin{tabular}{|c|c|c|c|c|}
\hline \multirow{2}{*}{ Climatic suitability class } & \multicolumn{2}{|c|}{ Number of days with stable temperature not less than $18^{\circ} \mathrm{C}$} & \multicolumn{2}{|c|}{ Annual precipitation } \\
\hline & Correlation coefficient & significance level & Correlation coefficient & significance level \\
\hline Low & -0.71 & 0.18 & -0.33 & 0.58 \\
\hline High & 0.93 & 0.02 & -0.16 & 0.79 \\
\hline Middle and high & 0.85 & 0.07 & 0.45 & 0.44 \\
\hline Total & -0.26 & 0.68 & -0.06 & 0.93 \\
\hline
\end{tabular}


The northern boundary of double-cropping rice cultivation shifted southwards and contracted eastwards in the Sichuan Basin in the 1970s compared to the 1960s. Rice is a hygrophilous crop, and cultivation of double-cropping rice is positively correlated with annual precipitation, which is an important factor in rice cultivation [14]. Temperature did not increase significantly in the 1970 s, but precipitation was reduced in the Jianghuai and Huanghuai areas [2]. As a result, the northern boundary for double-cropping rice cultivation shifted southwards and eastwards. Temperature has risen and precipitation decreased in the middle and lower reaches of the Yangtze River since 1979, which shows a warming and wetting trend [35,36], and has resulted in a northward shift in the northern boundary of double-cropping rice cultivation in the $1980 \mathrm{~s}$. The warmest 10 years during the past 60 years in China were recorded in the 2000s. The double-cropping rice cultivation area in China has shifted northwards and expanded westwards, consistent with the effects of active accumulated temperature, length of the rice growing season, and annual precipitation [37]. The expansion of the area of double-cropping rice cultivation [37] has occurred slightly further southwards than that documented in this present study largely because of climate change.

The double-cropping rice cultivation boundary has shifted northwards by 34-60 km in Zhejiang, Anhui, Hubei and Hunan because of recent climatic warming and corresponds to $\mathrm{a} \geqslant 10^{\circ} \mathrm{C}$ accumulated temperature of $5300^{\circ} \mathrm{C} / \mathrm{d}$ [22]. The present results indicate that the northern boundary has not shifted further northward, under the combined effect of climatic warming and moisture changes, in the 2000s compare with the northern boundary in the 1960s. Some plant species distribution boundaries appear to move northwards to a lesser extent and even southwards under climatic warming conditions, which might be due to the effect of water [23]. The difference in the movement range of the double-cropping rice cultivation boundary under climatic warming conditions in the present and previous studies is that the interactive effects of moisture and temperature are considered in the present study [22,37].

\section{Conclusions}

(1) Decadal changes in the distribution of double-cropping rice cultivation and climatic suitability in China are apparent. The total area climatically suitable for double-cropping rice cultivation was highest in the 1960s and subsequently showed an increasing trend at first and then a decreasing trend from the 1970s to the 2000s. However, the low climatic suitability area has decreased in extent, which implies that the moderate and high climatic suitability areas have increased. Among the latter, the high climatic suitability area has increased the most to about 4.4 times that of the 1990s and about four times that of the 1960s.
(2) The areas of double-cropping rice cultivation most sensitive to climatic change in China are mainly located in central Jiangsu, central Anhui, the eastern Sichuan Basin, southern Henan and central Guizhou. Transformation of areas between low and moderate climatic suitability has occurred in northern Zhejiang, southern Anhui and Hubei, and northern Guangxi. Transformation of areas between moderate and high climatic suitability has occurred in central Jiangxi and Leizhou Peninsula.

(3) Interaction between temperature and precipitation changes affects the northern boundary of double-cropping rice cultivation in China. The northward shift of the double-cropping rice cultivation boundary in response to climate warming is restrained by the effects of decreased precipitation. The northern boundary of double-cropping rice cultivation shifted southwards and contracted eastwards in the 1970s, and extended northwards in the 1980s. However, the northern boundary has not shifted northwards because of climate warming in the 2000s.

This work was supported by the State Key Development Program of Basic Research (2010CB951303), the Special Fund for Agroscientific Research in the Public Interest (200903003), and the Basic Operation Cost of China Meteorological Administration (CMA).

1 Wang S W, Ye J L, Gong D Y, et al. Construction of mean annual temperature series for the last one hundred years in China (in Chinese). J Appl Meteorol Sci, 1998, 9: 392-401

$2 \mathrm{Yu} \mathrm{H} \mathrm{Y,} \mathrm{Liu} \mathrm{S} \mathrm{H,} \mathrm{Zhao} \mathrm{N,} \mathrm{et} \mathrm{al.} \mathrm{Characteristics} \mathrm{of} \mathrm{air} \mathrm{temperature}$ and precipitation in different regions of China from 1951 to 2009 (in Chinese). J Meteorol Environ, 2011, 27: 1-11

3 Si D, Ding Y H, Liu Y J. Decadal northward shift of the Meiyu belt and the possible cause. Chin Sci Bull, 2010, 55: 68-73

4 Fye F K, Stahle D W, Cook E R. Paleo climatic analogs to twentieth-century moisture regimes across the United States. Bull Am Meteorol Soc, 2003, 84: 901-909

5 Woodhouse C A, Overpeck J T. 2000 years of drought variability in the central United States. Am Meteorol Soc, 1998, 79: 2693-2714

$6 \mathrm{Ma} \mathrm{Z} \mathrm{J,} \mathrm{Gao} \mathrm{Q} \mathrm{H.} \mathrm{Climate} \mathrm{changes} \mathrm{of} \mathrm{China} \mathrm{in} \mathrm{the} \mathrm{quaternary} \mathrm{period}$ and analysis on drought disasters of north China in the future (in Chinese). Quat Sci, 2004, 24: 245-251

7 Wang S W, Zhu J H. A review of overseas study on inter decadal variability (in Chinese). Acta Meteorol Sin, 1999, 57: 376-384

8 Ma Z G. Relationships between the drought trend in North China and transitional change and pacific decadal oscillation (in Chinese). Chin Sci Bull (Chin Ver), 2007, 52: 1199-1206

9 Yue T X, Fan Z M, Liu J Y. Changes of major terrestrial ecosystems in China since 1960. Glob Planet Change, 2005, 48: 287-302

10 Cooperative Agricultural and Forest Crop Regionalization Group in China. Agricultural and Forest Crop Climate Regionalization in China (in Chinese). Beijing: China Meteorological Press, 1987. 36-55

11 Li S K. Agricultural Climate Resources and Agricultural Climate Division in China (in Chinese). Beijing: Science Press, 1988. 1-7

12 He Q J, Zhou G S. The climatic suitability for maize cultivation in China. Chin Sci Bull, 2012, 57: 267-275

13 Ding Y. Rice Cultivation Science in China (in Chinese). Beijing: Agricultural Press, 1961. 101-180

14 Duan J Q, Zhou G S. Climatic suitability of double rice planting regions in China (in Chinese). Sci Agri Sin, 2012, 45: 218-227

15 Zhong F N, Liu S F. Analyses of rice production pattern in China (in Chinese). Chin Rur Econ, 2007, 39-44 
16 Gao J, Liu Y S. Climate warming and land use change in Heilongjiang Province, Northeast China. Appl Geogr, 2011, 31: 476-482

17 Hickling R, Roy D B, Hill J K, et al. A northward shift of range margins in British Odonata. Glob Change Biol, 2005, 11: 502-506

18 Joshua J L, Shafer S L, White D, et al. Projected climate-induced faunal change in the Western Hemisphere. Ecology, 2009, 90: 588597

19 Hamann A, Wang T. Potential effects of climate change on ecosystem and tree species distribution in British Columbia. Ecology, 2006, 87: 2773-2786

20 Weng E S, Zhou G S. Modeling distribution changes of vegetation in China under future climate change. Environ Model Assess, 2006, 11: 45-58

21 Esteve-Selma M A, Martínez-Fernández J, Hernández-García I, et al. Potential effects of climatic change on the distribution of Tetraclinis articulata, an endemic tree from arid mediterranean ecosystems. Clim Change, 2011, doi: 10.1007/s10584-011-0378-0

22 Yang X G, Liu Z J, Chen F. The possible effects of global warming on cropping systems in China I. The possible effects of climate warming on northern limits of cropping systems and crop yields in China (in Chinese). Sci Agri Sin, 2010, 43: 329-336

23 Crimmins S M, Dobrowski S Z, Greenberg J A, et al. Changes in climatic water balance drive downhill shifts in plant species' optimum elevations. Science, 2011, 331: 324-327

24 Shao P, Zeng X D. The impact of interannual climate variability on the mean global vegetation distribution (in Chinese). Acta Ecol Sin, 2011, 31: 1494-1505

25 Thornton P E, Running S W, White M A. Generating surfaces of daily meteorological variables over large regions of complex terrain. J Hydrol, 1997, 190: 214-251

26 Phillips S J, Dudík M. Modeling of species distributions with Maxent: New extensions and a comprehensive evaluation. Ecography, 2008,
31: $161-175$

27 Jaynes E T. Information theory and statistical mechanics. Phys Rev, 1957, 106: 620-630

28 IPCC. Climate Change 2007: Synthesis Report. Contribution of Working Groups I, II and III to the Fourth Assessment Report of the Intergovernmental Panel on Climate Change. Geneva, IPCC, 2007

29 Ren G Y, Guo J, Xu M Z, et al. Climate changes of China's mainland over the past half century (in Chinese). Acta Meteorol Sin, 2005, 63: 942-956

30 Fan Z M, Yue T X, Chen C F, et al. Spatial change trends of temperature and precipitation in China (in Chinese). J Geo-Inform Sci, 2011, 13: 526-533

31 Lin E D, Wang J H. The sensitivity and vulnerability of China's agriculture to global warming (in Chinese). Rur Eco-Environ, 1994, 10: $1-5$

32 Zhang T, Zhu J, Wassmann R. Responses of rice yields to recent climate change in China: An empirical assessment based on long-term observations at different spatial scales (1981-2005). Agr Forest Meteorol, 2010, 150: 1128-1137

33 Yang X, Sun F, Lin E D, et al. Sensitivity and vulnerability of rice to climate change in China (in Chinese). J Nat Disa, 2004, 13: 85-89

34 Zhu H G, Zhou S D. Vulnerability analysis of southern rice to climate change-Taking Jiangxi Province as an example (in Chinese). Res Agr Modern, 2010, 31: 208-211

35 Gong D Y, Ho C H. Shift in the summer rainfall over the Yangtze River valley in the late 1970s. Geophys Res Lett, 2002, 29: 1436

36 Zhang Q, Wu G Q. The large area flood and drought over Yangtze River valley and its relation to the South Asia High. Acta Meteorol Sin, 2001, 59: 569-577

37 Song Y L, Liu B, Zhong H L. Impact of global warming on the rice cultivable area in southern china in 1961-2009 (in Chinese). Adv Clim Change Res, 2011, 7: 259-264

Open Access This article is distributed under the terms of the Creative Commons Attribution License which permits any use, distribution, and reproduction in any medium, provided the original author(s) and source are credited. 